\title{
ERRATUM
}

\section{Erratum to: Target grouping in visual search for multiple digits}

\author{
Kenith V. Sobel • Amrita M. Puri • Jared Hogan
}

Published online: 24 October 2014

(C) The Psychonomic Society, Inc. 2014

\section{Erratum to: Atten Percept Psychophys}

\section{DOI 10.3758/s13414-014-0761-9}

The upper portions of Figs. 2, 3, 4, and 5 were missing in the published article. The correct figures appear below.
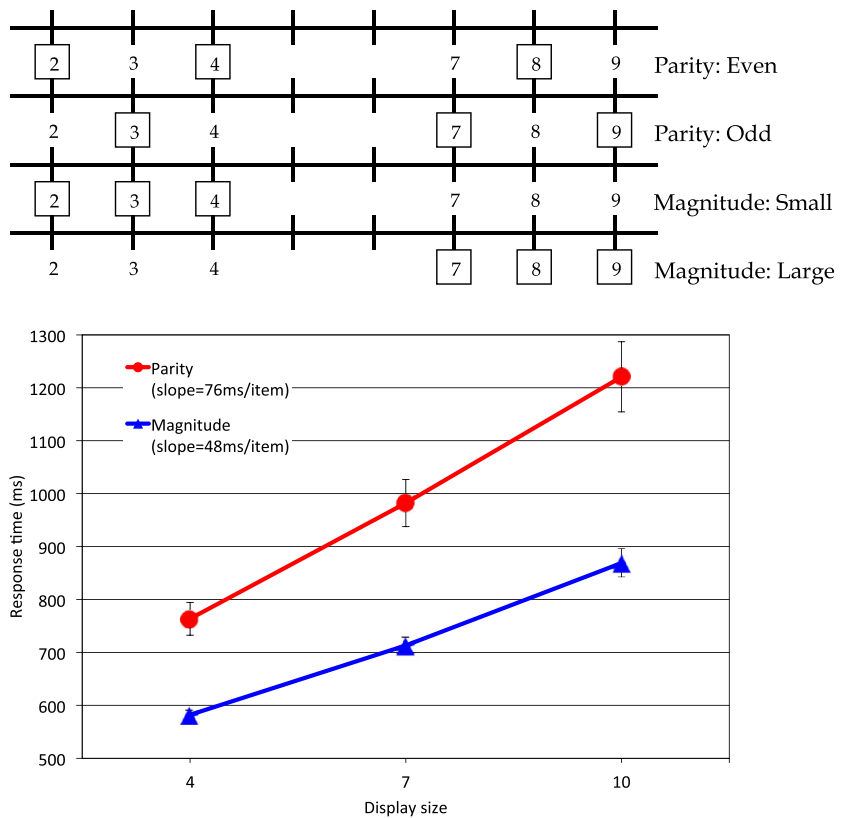

Fig. 2

The online version of the original article can be found at http://dx.doi.org/ 10.3758/s13414-014-0761-9.

K. V. Sobel $(\varangle) \cdot$ A. M. Puri $\cdot$ J. Hogan

Department of Psychology and Counseling, University of Central Arkansas, 201 Donaghey Ave., Mashburn Hall 260, Conway, AR 72035, USA

e-mail:k.sobel@mac.com
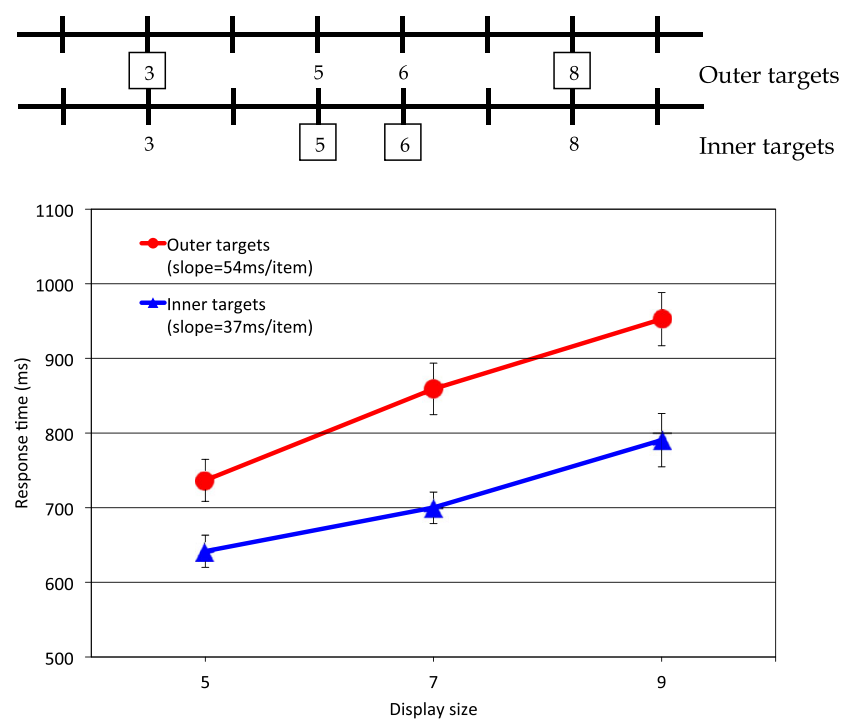

Fig. 3
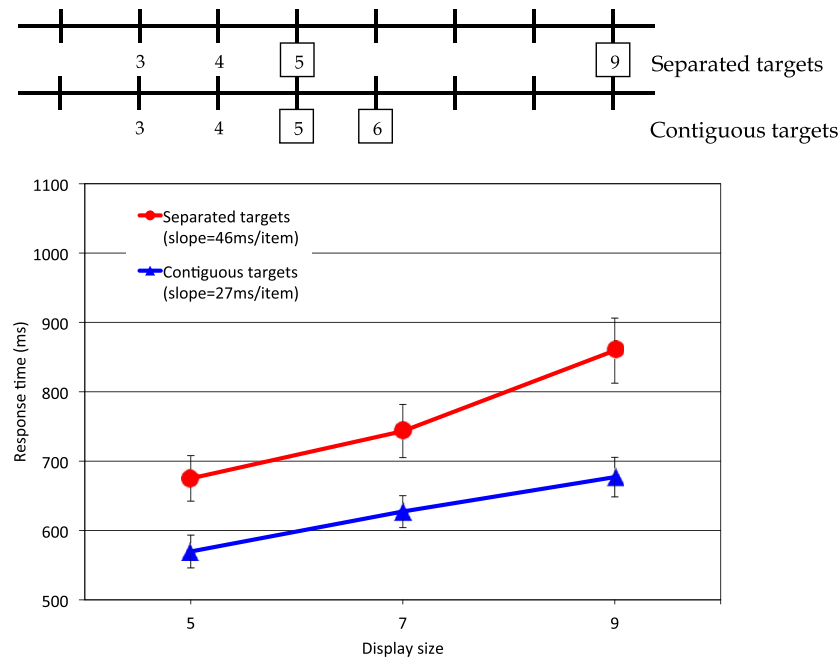

Fig. 4 

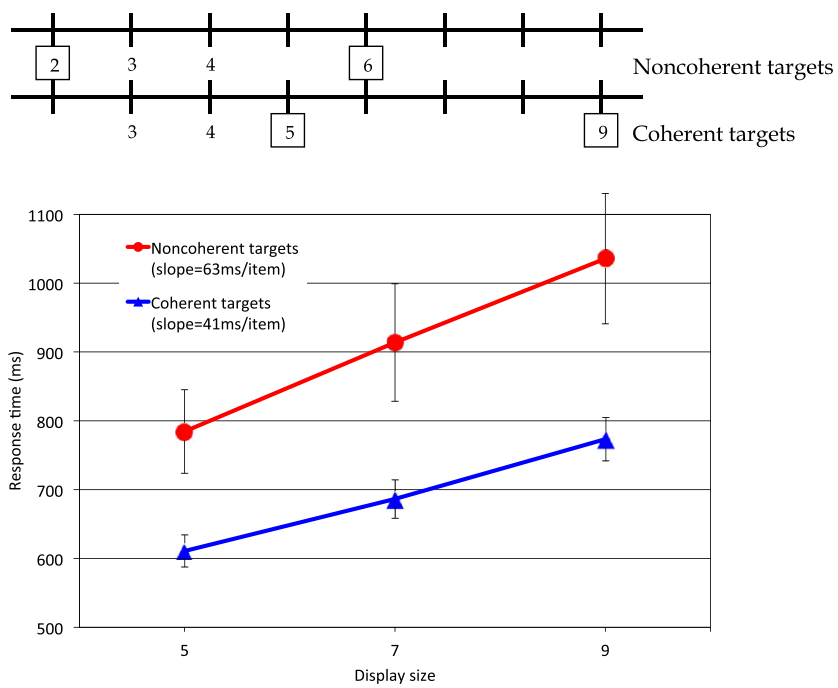

Fig. 5 